\title{
EFFECTIVENESS OF INSTITUTIONAL SERVICES FOR CHILDREN IN NEED OF CARE AND PROTECTION: A REVIEW
}

\author{
Raj Kumar Bandi \\ PhD Research Scholar, Department of Social Work, Osmania University, Hyderabad, Telangana, \\ India
}

Article DOI: https://doi.org/10.36713/epra8384 DOI No: 10.36713/epra8384

\begin{abstract}
The Nation's development depends on the development of children. Child must be encouraged to live in a family environment which gives an atmosphere of happiness, understanding, love, affection and emotional support for development of child's personality. The growth, development and personality of children is depended on the environment where the children grown up. Children are being institutionalized with various reasons such as destitution due to death of parents, poverty, inability of parents, unconducive family environment and health issues. As the children are living in the institutions away from their parents, it effects on physical, psychological and emotional development of children. The Government mandated child care institutions to maintain the minimum standards for providing effective rehabilitation services for children in need of care and protection. The child care institutions were managed by Government and Non-Government Organisations. Many studies have been conducted to see the services provided by child care institutions really meeting the needs of the children for their development to attain their goals and mainstreaming in the society.
\end{abstract}

KEY WORDS: Vulnerability, protection, institutions, rehabilitation, development.

\section{INTRODUCTION}

Any child who has been deprived of his or her right to a childhood is child in need of care and protection. Poverty, alcoholism, large family size, death of parents, single parent, step parents, children of diseased parents, sexually victimized children, abnormal children and unprotective environment were the various factors involved in the vulnerability of children. Various categories of children were admitted in child care institutions namely orphans, semi orphans, children of prisoners, children of sex workers, children of broken families, missing children, street children, child beggars, child labourers, children with disabilities, children suffering from incurable diseases, children indulging in substance abuse, exploited children, children affected by manmade disasters, natural calamities and emergencies, HIV infected or affected children and those parents were unable to control their children.
So far, the most common form of service for children in need of care and protection has been institutionalisation. Institutionalisation keeps children away from personal touch and homely atmosphere, which is necessary for growth and development of the child. Therefore, institutionalisation should, as far as possible, be avoided. However, institutional care may useful in case of deserted or dependent children, who have lost either one or both parents or who are otherwise incompetent to look after them or those children who cannot be supported by their parents. The importance of the home and the family in the growth and development of the child is accepted by all. Love and affection are as important as food and shelter. Therefore, as far as possible, a child should be looked after in his home. Where institutionalisation cannot be avoided, the conditions in the institution should be as near the home. The services for the children in the context of child welfare programmes are classified into institutional and non-institutional services applicable to both normal and special children. 


\section{SJIF Impact Factor 2021: 8.013| ISI I.F.Value:1.241| Journal DOI: 10.36713/epra2016 ISSN: 2455-7838(Online) \\ EPRA International Journal of Research and Development (IJRD)}

\section{LITERATURE REVIEW}

Sreepriya C.K. (2008) investigated on problems in the administration of social welfare programmes in Kerala regarding institutional services for children in need of care and protection. The administration of the government sector was well defined but there is no uniform pattern among the non-government organisations. Only seven per cent of the staff were professionally qualified. The government and non-government sectors exhibit poor administration of institutional service and provide low quality of services. All institutions in the government sector and most of the institutions in the non-government sector have weak infrastructure facilities.

Zeynep Simsek, Nese Erol, Didem Oztop and Kerim Munir (2007) compared a community sample of similarly aged children and adolescents raised by their own families to the prevalence of emotional and behavioural problems, as well as associated risk and protective factors, reported by teachers among institutionally reared children and adolescents reared in Orphanages in Turkey. Young children in orphanages had more emotional and behavioural difficulties than older children in orphanages and children in the community.

Suntinah and Siti Aminah (2018) investigated the various forms of abuse and neglect suffered by children in Indonesian orphanages. The services given at orphanages were found to be satisfactory, but the children had been subjected to some form of violence, particularly physical and psychological abuse. Caregivers, friends, and elders were the perpetrators of the assaults.

V.J.Kochuthresia (1990) studied on Residential Child Care Institutions in Kerala with special reference to their organizational characteristics examined the structural and functional characteristics of the institutions and investigated the staff and children to how extent they were satisfied with various facilities provided in the institutions. The primary objective of child care institutions is to provide educational facilities to the children. Keeping education as the primary objective, the residential child care institutions almost ignored the ultimate objective of rehabilitation. Girls' institutions were having a more formalized, centralized structure and vertical mode of communication compared to the boys' institutions. Consequently, girls' institutions tend to be governed by more rules, regulations and other formalities. Most of the institutions served four meals per day including non-vegetarian food. A medical doctor was available as one of the staff only in two institutions, children of remaining institutions were usually taken to the nearby government or private hospitals for treatment as and when required. More than half of the institutions were not following the recommended number of bathrooms and toilets stipulated in the minimum standards in child care institutions. A few institutions had the provision for cots and pillows, most of the institutions provided mattresses and bet sheets. Less than half of the institutions did not have proper arrangements in the institutions for children to keep their personal belongings in terms of trunk boxes or cupboards. The staff, as well as children, were highly satisfied with the physical facilities provided in the institutions. Compared to the staff, it was highly extended to the children. Regarding the educational facilities, maximum attention was paid by the institutions towards the educational achievement of the children by sending regularly to the schools either of their own management or to other managements. Recreational facilities were provided in most of the institutions in terms of conducting cultural programmes, sports and games, excursions etc., but both the staff and children were not satisfied with the recreational facilities they had. No proper rehabilitation measures were taken in the institutions like marriage, employment etc. Irrespective of the family situations, most of the children were reintegrated with their parents or relatives or guardians.

The National Commission for Protection of Child Rights (2019) critically assessed 50 child care institutions administered by the Government and NGOs in 19 districts in in Odisha. Only 44 per cent child care institutions had basic facilities such as proper toilets, bathrooms, air conditioning in the summer, safe drinking water, gas stoves for cooking, so on and that many homes were operating in an unsanitary manner without providing the basic need of care. Trained Counsellors were appointed in 46 per cent child care institutions to dealt with psychosocial issues of children and their emotional care. 52 per cent child care institutions had a separate counselling room on the premises for guiding and counselling of all children, as well as specific mental health interventions for those who needed them. Children's Committees were constituted in 80 per cent child care institutions. Management Committee was constituted in 74 per cent child care institutions for the management of the institution and to monitor the progress of the children. Children were not produced before Child Welfare Committee in 8 per cent child care institutions. Sickroom/first aid room was made available in 60 per cent child care institutions to take care of sick children. Child helpline - 1098 was displayed prominently in 72 per cent child care institutions to address the issues of children. Programme for tracking of a missing child was implemented in 60 per cent child care institutions by uploading the information about missing/ orphan/ abandoned children on the portal. 


\section{EPRA International Journal of Research and Development (IJRD)}

Henry Zodinliana Pachuau (2014) compared children in need of care and protection from community and institutions in Mizoram. Poverty alleviation programmes or employment generation programmes should be undertaken to consider consequences of poverty on children and suitable measures to reduce their vulnerability. The convergence among the line departments should be developed to cater for the services of children in different areas.

The assertive views of Evie Browne (2017) in the work entitled Children in Care Institutions highlighted an overview of children in institutions/ orphanages worldwide, causes and interventions to prevent the exploitation of institutionalized children. Estimates show that about 2.7 million children under 18 years of age are living in institutions worldwide. Even though the sources are available, the data is not reliable due to the under-reporting of children and unregistered institutions. Not all the children in the institutions are orphans. More than 50 per cent of children in institutions have a single parent. The significant causes for children institutionalized are poverty, the inability of parents, and the perception that better care and education could be provided at an institution. Children with special needs are at a high risk of institutionalisation. The most common forms of abuse reported are physical violence, sexual violence perpetrated by staff or peers, neglect, undernutrition, mistreatment and child labour within the institution. Additionally, poor regulations and oversight mean that abuse is often rampant. There is a high risk of sexual exploitation by volunteers because many residential care centres offering volunteer placements without police clearance reports, background information and lack of supervision on volunteers when they are spending time with children. The most common adverse effects of children who grow up in residential care include developmental delays, behavioural problems, attachment disorders, lack of life skills, and difficulty forming and maintaining healthy relationships. It was clearly mentioned that residential care should be a last resort for children separated from their parents, following family support, community support, and fostering. It supports strongly that, deinstitutionalisation and reintegration of families whenever possible and provision of extra support to families as the best intervention.

Hamsaveni (2015) examined the services of children homes for care, protection and rehabilitation of Destitute Children in Mysore City of Karnataka State The most significant way of rehabilitation adopted for boys was providing employment and for girls was getting them married off. In all the girls' institutions, the inmates were trained on household activities such as cooking, care for the family and maintenance of house for leading a successful family life after marriage. It was suggested that adequate financial assistance should be provided to child care homes from the Government to meet the needs of the children and along with that a proper monitoring of funds utilized for the children purpose must be ensured by them.

Tomba Chingtham (2014) analysed causes and facilities of destitute children in the children's homes of Imphal and Manipur. The major push factors identified for destitute children were broken families ( 23 per cent), extremely poor and helpless single parent of both parents (21 per cent), AIDS victim parents (18 per cent), parents died of illness other than AIDS (18 per cent), insurgency problems ( 9 per cent), parents died either in an accident or committed suicide ( 8 per cent), abandoned by parents (3 per cent). Regarding the facilities provided by children homes to the destitute children, 95 per cent of children were satisfied with food facilities whereas 90 per cent of children were satisfied with educational and clothing facilities, 76 per cent of children were satisfied with the healthcare system. 76 per cent of children attending Govt schools and the remaining 24 per cent attending private schools for education. Vocational training for destitute children was not satisfactorily conducted in the children's homes.

Save the Children (2014) in its work entitled Institutional Care believed that, placing children in child care institutions especially below the age of 3 years, is hazardous to their health and development. Children were best cared for when they grew either in their own family or family-based setting in their own community. In the world, for every five children living in child care institutions, four children have parents who could care for them. About 2 million children worldwide are provided with poor quality institutional care services, which affects the physical and psychological development of children. Leaving children in child care institutions are more vulnerable to neglect, violence and abuse which are undetected and unreported. Most of the child care institutions are running without adequate standards, lack of personnel and the feelings like love, care and affection cannot be seen. Due to lack of stimulation and attention, children in institutional care are more likely to have stunted growth and have lower IQ. Deinstitutionalization of children is recommended by providing alternative family-based care options such as kinship care, fostering and adoption. It can be achieved through reforming the current child care system, including legal and policy change, retraining care and social work staff, reallocating the budget from institutional to family-based care, and recruiting family-based carers.

Hilda Sewe Ounah (2011) conducted study on Rehabilitation and Education for Street Children in Makadara and Kamukunji Districts of Nairobi. The 


\section{EPRA International Journal of Research and Development (IJRD)}

services offered in the rehabilitation centres were assessment, rehabilitation, counselling, health and education. The study revealed that 40 per cent children had expressed their satisfaction towards the provision of sufficient food and other facilities. Regarding education, street children were being provided proper education along with non-street children, to enhance their sense of belonging and self-esteem for achieving future expectations. It has been found that providing a conducive environment with proper sanitation in the rehabilitation centres is the critical need for street children in the health care system.

Marinus H. van IJzendoorn and 9 others (2011) in their work entitled Children in Institutional Care as "Delayed Development and Resilience", mentioned that the children in institutional care often suffer from dramatic developmental delays, but not every child is affected in the same way and to the same extent. It also affects their physical development, cognitive development, hormonal development and attachment security of children, even when their basic needs such as food, clothes, etc were adequately met.

Lorraine Sherr, Kathryn J. Roberts and Natasha Gandhi (2017) discussed the experiences of child violence in child care institutions. The review of research studies, books, and papers was focused on four aspects: incidence of abuse, peer-on-peer violence, strategies to reduce abuse in institutions, and the impact of institutions on cognitive and social development. According to the studies, child abuse exists between the ages of 7 and 20. There was no information about children under the age of seven years. 89 per cent of children aged 5-14 years who were institutionalised between the ages of 0 and 4 years reported that they had at least one experience of abuse. Only one study revealed the review of peeron-peer violence, with 9 per cent of victims reporting their perpetrators to be teenagers aged 18 or older. The rate of abuse was higher among institutionalised children than among home-based children, according to a study of 80 institutionalised children and 50 home-based children.

Central Child Welfare Board (2015) analysed the status of Child Care Homes in Nepal. At the Central level, the Central Child Welfare Board and at the District level, the District Child Welfare Board monitoring the functioning of Child Care Homes in Nepal. For the regulation and strengthening of Child Care Homes, the Government of Nepal issued regulations and Standards for Operation and Management of Residential Child Care Homes in 2012. A total of 585 Child Care Homes were active in 45 districts, of which with three of them serving as juvenile detention facilities and four homes for children in need of care and protection were running under the Government. The remaining homes for children in need of care and protection were run by non-governmental organisations. Around 16000 children were accommodated in homes, half of them were boys and half of them were girls. There was no coordination between the government and the management of child care homes, no correct documentation, and no qualified staff were allocated to child care homes, according to the investigation.

The thematic report on Child Sexual Abuse in the context of Children's Homes and Residential Care (2019) described the experiences of child abuse in residential care between the 1940s and 2000s. From a sample of 191 individuals their experiences of sexual abuse in the context of residential care were drawn. The factors involved for being the children in residential care due to family disrupts which were mainly in terms of domestic violence, consuming alcohol, mental health issues and physical abuse. The most frequently reported perpetrators in the residential care context were caretakers, peers and older children. The children who were abused in residential care revealed that sexual abuse was occurred repeatedly to them, over a prolonged period. The victims described they had a lot of negative impacts during the time of abuse and in later stages of life which includes changing into criminal behaviour, occurrence of various mental health issues, increasing suicidal tendencies. Some of them reported that disability and long-term illness affected them as a consequence of sexual abuse towards them.

In the Survey on child abuse in Residential Care Institutions in Romania (2000), a sample of 3164 children in residential care institutions in the age group of 0-18 years was selected for collecting the information. Physical abuse by educational professionals and night caretakers was experienced by half of the children. In residential care organisations, the most common kind of sexual abuse between minors is homosexual relationships. Although it was much lower, older children as well as institutional employees exploited younger children.

Robert B. McCall (2013) reviewed the consequences of early institutionalization of children based on a database search of the literature, focused on the development of children while residents and post-institutionalized children who were transitioned from institution to family care. Institutionalized children had poorer physical, mental, emotional, and social development than children adopted from institutions. In many domains of their development, the adopted children showed significant catch-up growth. When children are adopted at their young age, there are no long-term implications of institutionalisation; nevertheless, when institutionalisation is continued, they exhibit increased rates of long-term inadequacies and issues in many domains of their lives. The interactions 


\section{EPRA International Journal of Research and Development (IJRD)}

between the caretaker and the child in institutions have a tremendous impact on the development of children, especially those with special needs. Deinstitutionalization and the establishment of comprehensive professional child welfare systems emphasizing family care alternatives were shown to be the preferred goal for the substantial development of children. It was suggested that for the majority of children, family care is likely to be the best alternative.

\section{CONCLUSION}

It is revealed that the causes involved in the institutionalization of children, status of child care institutions, services provided to children in the institutions for their rehabilitation, various issues faced by institutionalized children and how extent the children were satisfied with the services provided by institutions. It was estimated that, more than 2.7 million children were institutionalized worldwide. The studies show that more than half of the institutionalized children are not orphans. The children having single parent and both the parents were also institutionalised due to poverty or economic backwardness. Children face violence in the form of physical and psychological abuse from the Management of child care institutions as the Management was appointed without verifying their antecedent whether involved in any crime or immoral activity or convicted for any offence. The growth and development of children also delayed due to institutionalization when compared to the children reared in family-based environment. Most of the institutions are functioning with lack proper facilities and without proper rehabilitation measures. Institutionalization is the last resort for children after taking all the measures for growing up the children in community-based environment. Hence, to reduce the vulnerability among the children who are need of care and protection, poverty alleviation programmes and income generated activities shall be promoted. If necessary, keeping in view of the best interest of child, non-institutional care services such as sponsorship, foster care and adoption shall be implemented for making child live in the society.

\section{REFERENCES}

1. Aminah, S. (2018). NU SC. Children and Youth Services Review, \#pagerange\#. https://doi.org/10.1016/j.childyouth.2018.07.002

2. Browne, E. (2017). Children in care institutions. $1-18$.

3. Building, C. (2019). Report on inspection of Child Care Insitutions of Odisha by National Commission for Protection of. 1-7.

4. Care, I., \& Resort, T. H. E. L. (2014). Policy brief Institutional Care: The Last Resort All children thrive in a safe family environment and no child is placed in harmful institutions. May.
5. Child, C., \& Board, W. (2015). State of the Child Care.

6. Chingtham, T. (2014). Causes and Facilitis of Destitute Children in the Children Homes. 4(6), 50-53. https://doi.org/10.9790/7388-04645053

7. Chowdhry, P. (1995). Introduction to Social Work

8. Henry Zodinliana Pachuau (2014). Children in Need of Care and Protection in Mizoram: Social Work, Mizoram University, Aizawl

9. International Journal of Research in Engineering \& Social Sciences. (2015). 5(11), 25-34.

10. Justice, J. (2006). Data Base of Child Care Institutions. 2000, 1-120.

11. Kochuthresia V.J. (1990). Residential Childcare Institutions in Kerala: With special reference to their Organizational Characteristics. Ph.d Thesis. Mumbai: Tata Institute of Social Sciences.

12. Mccall, R. B. (2013). Review: The consequences of early institutionalization: can institutions be improved? - should they? 4, 193-201. https://doi.org/10.1111/camh.12025

13. Osei, A. (2019). The United Nations Convention on the Rights of the Child. Beginning With Brandon's Interest, 136-136. https://doi.org/10.1163/9789460913020_012

14. Ounah, H. S. (2011). The rehabilitation and education for street children, the case of Makadara and Kamukunji Districts, Nairobi. October.

15. Sherr, L., Roberts, K. J., \& Gandhi, N. (2018). Child violence experiences in institutionalised / orphanage care. Psychology, Health \& Medicine, January 2017, 1-27. https://doi.org/10.1080/13548506.2016.1271951

16. Simsek, Z., Erol, N., Öztop, D., \& Münir, K. (2007). Prevalence and predictors of emotional and behavioral problems reported by teachers among institutionally reared children and adolescents in Turkish orphanages compared with community controls is. 29, 883-899. https://doi.org/10.1016/j.childyouth.2007.01.004

17. Soares, C., \& King, S. (2019). Child sexual abuse in the context of children' $s$ homes and residential care.

18. Sreepriya C. $K$ (2008). Problems in the Administration of Social Welfare Programmes in Kerala: A Study with reference to Institutional Services for Children in Need of Care and Protection, Gandhian Studies (Social Work) Under the faculty of Social Sciences, Mahathma Gandhi University, Kottayam.

19. Survey on Child Abuse in Residential Coordinator: (2000).

20. Vorria, P., \& Lemare, L. (2011). Children in Institutional Care: Delayed Development and Resilience. https://doi.org/10.2307/41408755 